Nevşehir Bilim ve Teknoloji Dergisi Cilt 3(2) 15-24 2014

DOI: 10.17100/nevbiltek.210936

URL: http://dx.doi.org/10.17100/nevbiltek.210936

\title{
AlGaAs/GaAs Heteroyapılarda Öz Uyumlu Potansiyel Hesabı
}

\author{
Selman Mirioğlu ${ }^{1}$, Uğur Erkarslan ${ }^{1}$, Görkem Oylumluoğlu ${ }^{1, *}$ \\ ${ }^{1}$ Muğla Sıtkı Koçman Üniversitesi, Fen Fakültesi, Fizik Bölümü, 48000, Muğla
}

Özet

Bu çalışmada, birbirine paralel ikili, iki boyutlu elektron gazını (2BEG) modellemek için III-V grubu yarı iletken elementlerinden AlGaAs/GaAs heteroyapısının enerji bant dağılımı Schrödinger ve Poissson denklemlerinin öz uyumlu çözümüyle elde edilmiştir. $\mathrm{AlGaAs} / \mathrm{GaAs}$ heteroyapıların elektronik özellikleri katkılamanın 2BEG'in tek ve her iki tarafina yapılması durumunda katkılamanın bir fonksiyonu olarak incelenmiş̧ir. Ayrıca; enerji bant dağılımının Al konsantrasyonuna bağlı değişimi sistematik olarak araştırılmıştır.

Anahtar kelimeler: AlGaAs/GaAs heteroyapısı, 2BEG, iki kuyulu sistem

\section{Self-Consistent Calculation of the Potential at AlGaAs/GaAs Heterostructures}

Abstract

In this work, energy bant dispersion of AlGaAs/GaAs heterostructure, one of the III-V group elements of semiconductors is obtained by solving the Schrödinger and Poisson equations self-consistently for the modeling of double (bilayer) 2DEGs placed parallel. We investigate the electronic properties of $\mathrm{AlGaAs} / \mathrm{GaAs}$ heterostructures as a function of the doping level in a condition where we obtain several different donor exist on one side and on both sides of the 2DEG. Besides, changes in the energy bant dispersion due to different $\mathrm{Al}$ concentrations are systematically investigated for these systems.

Keywords: AlGaAs/GaAs heterostructure, 2DEG, Bilayer system.

*e-mail: gorkem@mu.edu.tr 


\section{Giriş}

Yariiletken teknolojisinde 80'lerin başında nano-yapıların bazı fiziksel büyüklüklerini ölçmek ve nano ölçekte malzeme üretmek maksadıyla kullanılabilecek bazı yöntemler ve aygıtlar geliştirilmiştir [1]. Bu çalışmalar, hem nanometre ölçeklerinde, fiziğin anlaşılmasını sağlamış hem de atom ve moleküllerin bir araya getirilmesi ve nanometre ölçeklerde işlevli yapıların oluşturulması ile de ortaya çıkan yeni teknolojik gelişmelere yol açmıştır.

$\mathrm{Bu}$ teknolojilerin itici güçlerinden biri yariiletken teknolojileridir. Düşük boyutlu yariiletken sistemlerden oluşan nanometre boyutunda elektronik ve optoelektronik cihazlar [2] bilgisayardan haberleşme endüstrisine, kullanılan devrelerin temel yapıtaşlarını oluşturmaktadır. Ayrıca temel fizik yasalarının anlaşılması ve sınanması için önemli laboratuvar özelliği göstermektedirler [3-5].

Kristal örgü sabitleri birbirine yakın, ancak enerji bant aralığı farklı olan AlGaAs ve GaAs gibi yariiletkenlerin oluşturulmasında yararlanılan en yaygın epitaksiyel yöntemler Moleculer Beam Epitaxy (MBE) [6-8], Molecular-Organic Chemical Vapor Deposition (MOCVD), Molecular-Organic Vapour Phase Epitaxy (MOVPE) teknikleridir. Heteroyapılar oluşturulurken gözlenmek istenen etkilere bağlı olarak özellikle son zamanlarda tek yönde büyütülerek oluşturulan iki boyutlu kuantum kuyuları, iki yönde büyütülerek oluşturulan [8-11], ve aygıtın üzerinde çeşitli kesme ve kapı yöntemleri kullanılarak elde edilen tek boyutlu kuantum telleri veya sifir boyutlu kuantum noktalar olarak [12] yapıların literatürde uygulama ve araştırma alanları çokça geniş yer tutmaktadır. Bu yapıların önemli uygulamalarından biride iki boyutlu elektron gazıdır [13]. İki boyutlu elektron gazı (2BEG) $\mathrm{AlGaAs} / \mathrm{GaAs}$ tabakalar halinde büyütülürken kristallerin üst üste geldiği eklem bölgelerinde oluşur. Heteroyapıların ara yüzeylerinde, düşük sıcaklıkta yük taşıyıcılarının düzleme dik yöndeki hareketleri kısıtlanırken, düzleme dik yönde uygulanan kuvvetli manyetik alan sistemi kuantumlayarak, elektronların Landau seviyelerine yerleşmesini sağlar [14]. Bu sistemlerin, temel kuantum taşınım deneyleri [15] gibi temel fizik araştırmalarının yapılması yanında kuantum algılayıcıları gibi teknolojik uygulamaları da vardır. Düşük boyutlu sistemlerin ayrıntılı olarak incelenmesi bu cihazların çalışma prensiplerinin anlaşı1masında önemli rol oynayacaktır.

$\mathrm{Bu}$ çalışmada, ilk olarak yariiletken malzemeler AlGaAs /GaAs heteroeklemlerinde oluşturulan birbirine paralel iki kuantum kuyusu için bant yapıları, yapı içindeki elektron davranışları gibi özellikleri Poisson denkleminin öz uyumlu çözümleri ile yapılmıştır. Ayrıca enerji bant dağılımının Al konsantrasyonuna bağlı değişimi sistematik olarak incelenerek tünelleme olasılıkları tartışılmıştır.

\section{Materyal ve Metot}

$\mathrm{Bu}$ çalışmada $\mathrm{Al}_{\mathrm{x}} \mathrm{Ga}_{1-\mathrm{x}} \mathrm{As}$, Al katkılı malzemenin yasak enerji aralığı; $\mathrm{x}<0,45$ için $E_{g}=1,424+1,247 x$ ve $x$ 'in daha büyük değerleri için $E_{g}=1,424+1,247 x+1,147(x-0,45)^{2}$ şeklindedir [16].

Öz uyumlu potansiyel hesabı, başlangıç olarak sisteme katkılamalarla elde edilen yük yoğunluğu Poisson denklemine yerleştirilir, sistemin potansiyeli elde edilir. Daha sonra Schrödinger denklemi çözülerek dalga fonksiyonu bulunur. Elde edilen dalga fonksiyonu yardımıyla elektron yoğunluğu tekrar elde edilir ve Poisson denklemi tekrar çözülür. Bu işlem elde edilen son potansiyel değeri ile bir önceki potansiyel değeri birbirine çok yakın değerde sonuç elde edene kadar devam eder (Şekil 1). Bu sürece öz 
uyumlu potansiyel hesabı denir. İşlem tamamlandığında sistemin elektron dağılımı, 2BEG oluşumu ve buna bağlı bant bükülmeleri ile potansiyel profili elde edilmiş olur.

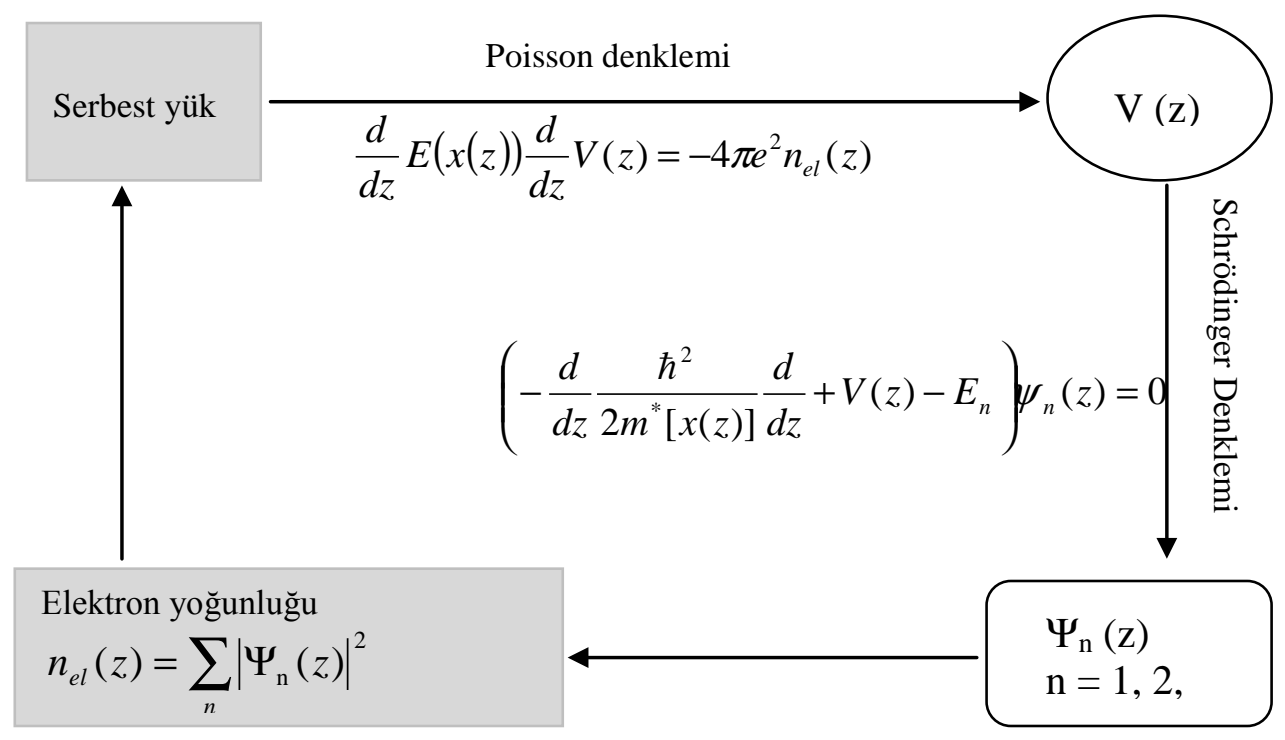

Şekil 1. Öz uyumlu potansiyel hesabı şematik gösterimi

\section{Bulgular}

\section{1. Çift Katmanlı Heteroyapının Sistematik İncelenmesi}

Bu bölümde, uygun katman kalınlıkları ve donör katkılaması ile oluşturulan sistemde çift kuyulu (bilayer) yapı oluşturulmuş ve yapı içindeki elektron dağılımı ve tuzaklama potansiyeli Poisson denkleminin öz uyumlu çözümüyle sistematik olarak incelenmiştir [17]. Ayrıca kuyular içindeki enerji düzeylerinin değerlerini karşıllklı olarak etkileyen faktörler sistematik olarak araştırılmıştır. Enerji düzeylerinin birbirinden farklı olması, tünelleme olayını etkileyen en önemli parametrelerden biridir. Yapılan deneylerde, her iki kuyudaki enerji düzeyleri birbirine eşit olduğunda tünelleme olayı gerçekleşmekte ve kuyuların mobilitelerinin birbirinden farklı olması durumunda iletkenlik azalmaktadır.

Bu çalışmada ilk olarak z-yönünde $300 \mathrm{~nm} \mathrm{Al}_{x} \mathrm{Ga}_{1-\mathrm{x}}$ As alttaş üzerine $10 \mathrm{~nm}$ GaAs sonrasında 4 $\mathrm{nm}$ bariyer ve tekrar $9 \mathrm{~nm}$ GaAs üzerine $22 \mathrm{~nm} \mathrm{Al}_{\mathrm{x}} \mathrm{Ga}_{1-\mathrm{x}} \mathrm{As}$ büyütülüp en üst tabaka $10 \mathrm{~nm}$ GaAs ile sonlandırılmış bir örnek için hesaplamalar yapılmıştır (Şekil 2). Donör yoğunluğu $1.3 \times 10^{20} \mathrm{~cm}^{-3}$ olarak alınmıştır.

Heteroyapının külçe (bulk) yapıda olması ve heteroeklem bölgelerinde örgü uyumunun çok iyi olması sebebiyle yapı içerisinde yer alan elektronların termal dengede olduğu varsayımı kullanılmaktadır. Eğer T sıcaklığında N parçacıklı sistem termal dengede ise tüm $\mathrm{N}$ durumları üzerinden ortalaması alarak hesaplanmaktadır. Yani bir sistemin termal elektrokimyasal dengede bulunması, tüm sistemin bir $\mathrm{E}_{\mathrm{F}}$ ile temsil edilmesi anlamına gelmektedir. Burada malzeme sıcaklığı T =0,4 K olarak alınmıştır. 


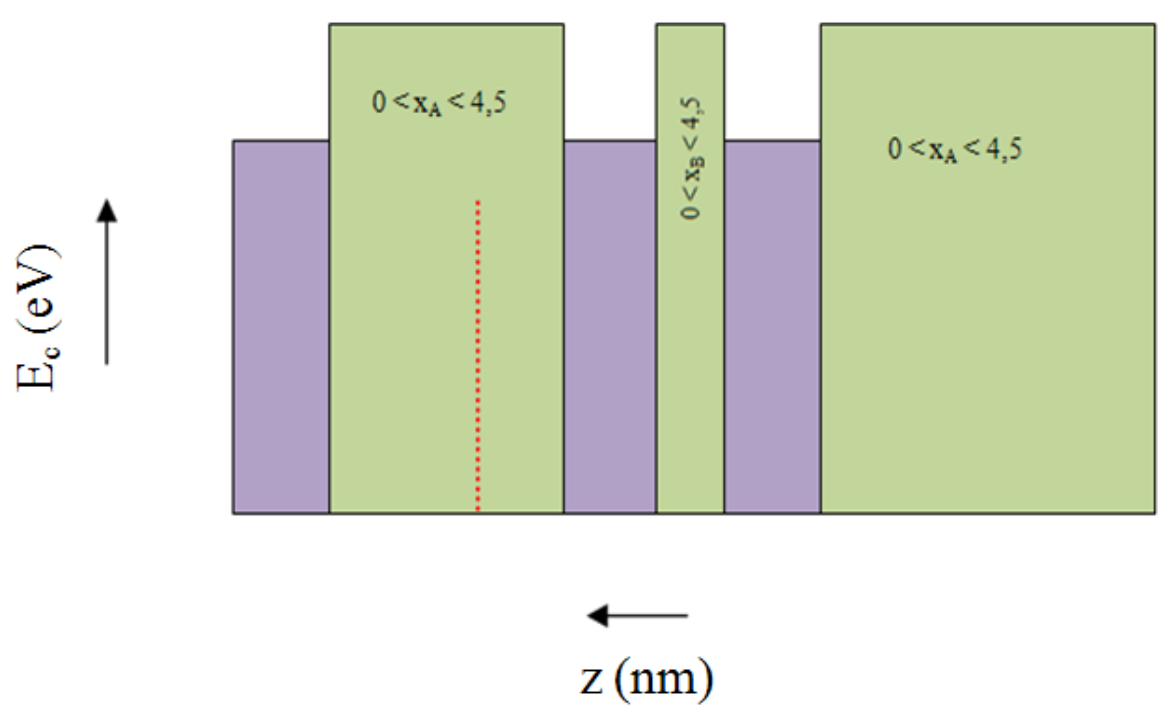

Şekil 2. İki farklı heteroyapının iletkenlik bant durumları ( $\mathrm{x}_{\mathrm{A}}$ ve $\mathrm{x}_{\mathrm{B}}$ farklı Al katkı oranını göstermektedir)

Al katkısı GaAs yariiletkenlerin yasak enerji bant aralığını artırmaktadır. Al katkısı değiş̧tirilerek bilayer sisteminin orta bölgesindeki $\mathrm{Al}_{x} \mathrm{Ga}_{1-\mathrm{x}} \mathrm{As}$ yariiletkeninin neden olduğu potansiyel bariyeri yüksekliği değiştirilmiş ve böylece kuyu içerisindeki elektron yoğunluğu ve tünelleme olasıllğı sistematik olarak incelenmiştir. Birbirinden 4nm genişliğinde bariyer ile ayrılan iki kuantum kuyulu (bilayer) bir heteroyapının $\mathrm{x}_{\mathrm{A}}$ (kuyular arasındaki bariyer bölgesi hariç tüm yapının Al-katkısı) ve $\mathrm{x}_{\mathrm{B}}$ (kuyuların ara bölgesinde kalan bariyerin Al-katkısı) değerleri birbirinden bağımsız değiştirilmiş̧ir. Bariyerden geçiş, elektronun enerjisi, bariyer yüksekliği ve bariyerin kalınlığı ile ilişkilidir. Genel bir ifadeyle bariyerden geçiş,

$$
T=\left[1+\frac{\Delta V^{2} \sin ^{2} k_{2} d}{4\left(E-V_{G a A s}\right)\left(V_{A l G a A s}-E\right)}\right]^{-1}
$$

şeklindedir. Burada $\mathrm{k}_{2}$;

$$
k_{2}=\frac{\sqrt{2 m\left(V_{\text {AlGaAs }}-E\right)}}{\hbar}
$$

dir. $\Delta \mathrm{V}$ ise $\mathrm{Al}_{\mathrm{x}} \mathrm{Ga}_{1-\mathrm{x}} \mathrm{As}$ ile GaAs arasındaki iletkenlik bandı enerji seviye farkıdır.

Şekil 2 örneğinde iki kuyu arasında kalan bariyerin dışındaki $\mathrm{Al}_{x} \mathrm{Ga}_{1-\mathrm{x}} \mathrm{As}$ katmanlarının Alkonsantrasyonu x=0,4'te tutulup, kalınlığ $1 \mathrm{~d}=4 \mathrm{~nm}$ olan aradaki katmanının Al-konsantrasyonu $0<\mathrm{x}_{\mathrm{B}} \leq$ 0,4 aralığında farklı değerler için incelenmiş̧ir (Şekil 3). 


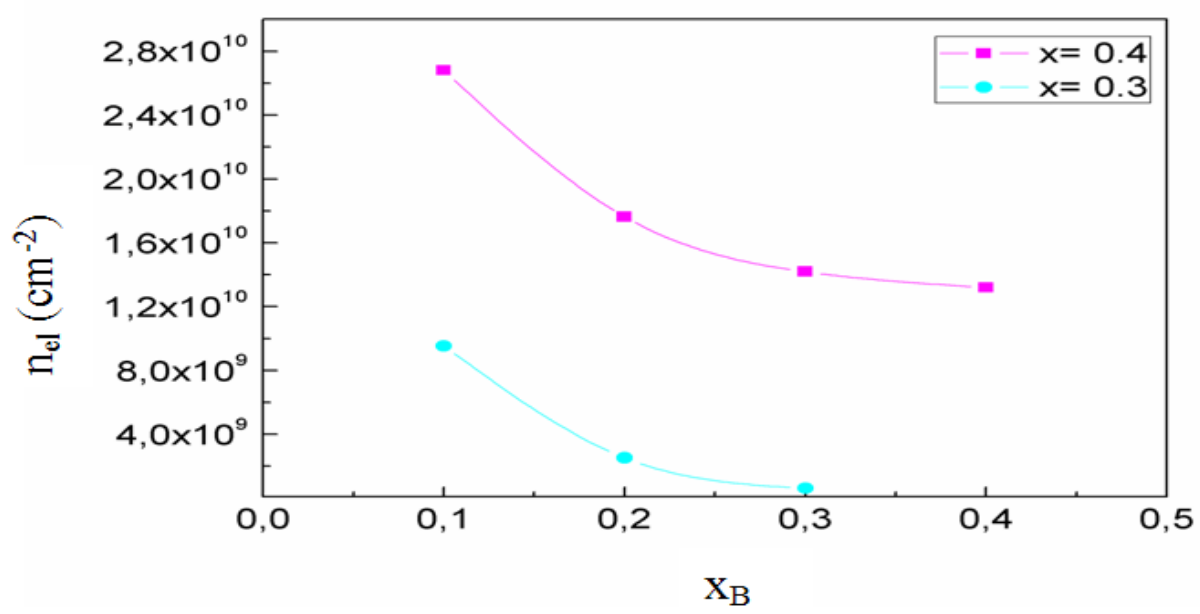

Şekil 3. Bariyer Al-katkısına bağlı olarak kuyu içindeki elektron yoğunluk değişimi

a)

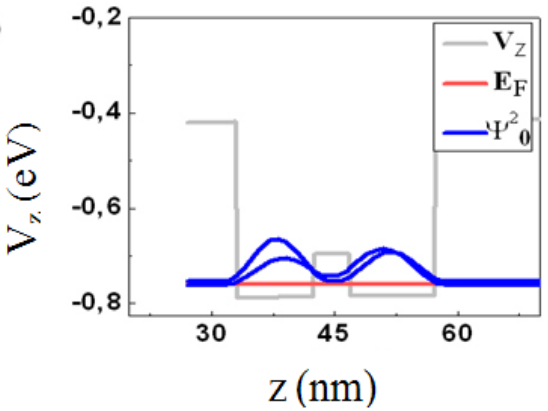

c)

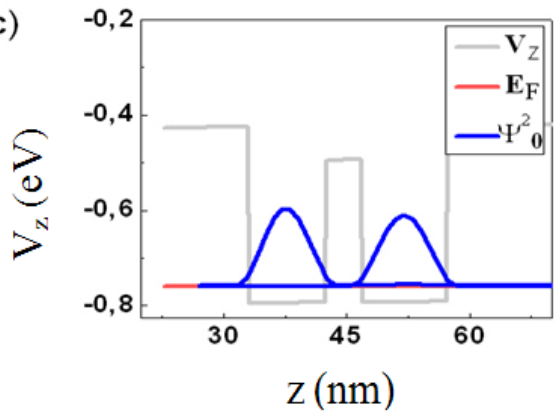

b)

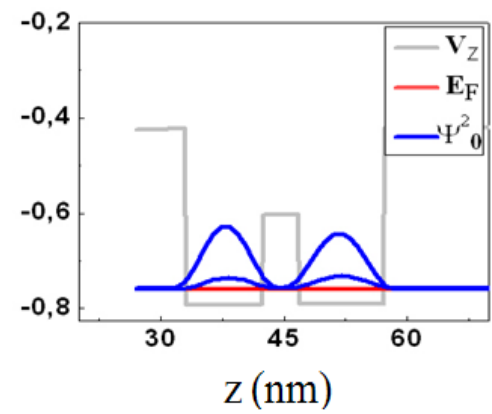

d)

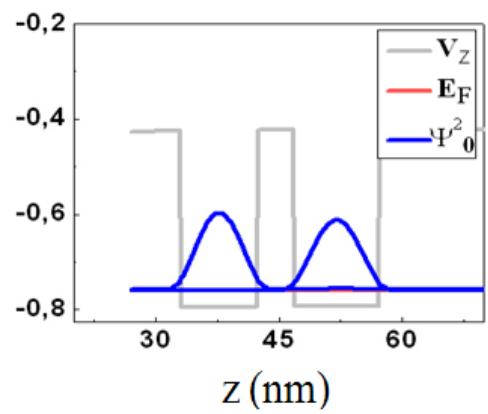

Şekil 4. Bariyer yüksekliğine bağlı olarak kuyu içinde elektronun bulunma olasılığı (Al-katkıları; (a) $\mathrm{x}_{\mathrm{B}}=0.1$, (b) $\mathrm{X}_{\mathrm{B}}=0.2$, (c) $\mathrm{x}_{\mathrm{B}}=0.3$ ve (d) $x_{B}=0.4$ )

Şekil 4 de iki kuantum kuyulu heteroyapının enerji bant diyagramı gösterilmiştir. Burada, kuyular arasında kalan bariyerin yüksekliğini belirleyen parametre Al katkısıdır. Bariyer yüksekliğine bağlı olarak elektronların taban durum enerjisinde kuyularda bulunma olasılık yoğunlukları bu şekil üzerinde mavi ile çizdirilmiştir. Bariyer yükseklikleri değiştikçe tünelleme olasılığının verilen parametre değerleri için $\mathrm{x}_{\mathrm{B}}<0,3$ olması durumunda arttı̆̆ gözlemlenmiştir.

\section{2. Çift kuyu arasındaki bariyer kalınlığına bağlı durumlar}

$\mathrm{Bu}$ kısımda örneğin katkı yoğunluğu, kuyu arasındaki bariyer dışında kalan katmanların kalınlıkları, sıcaklık vb. parametreler sabit alınmış, değişim sadece bariyer kalınlığı üzerinden yapılmıştır. 
Farklı bariyer kalınlıkları ile elde edilen potansiyel profilleri Şekil 5'te gösterilmektedir. Tüm yapı için $\mathrm{Al}$, konsantrasyonu $\mathrm{x}=\mathrm{x}_{\mathrm{B}}=0,3$ katkılanmıştır.
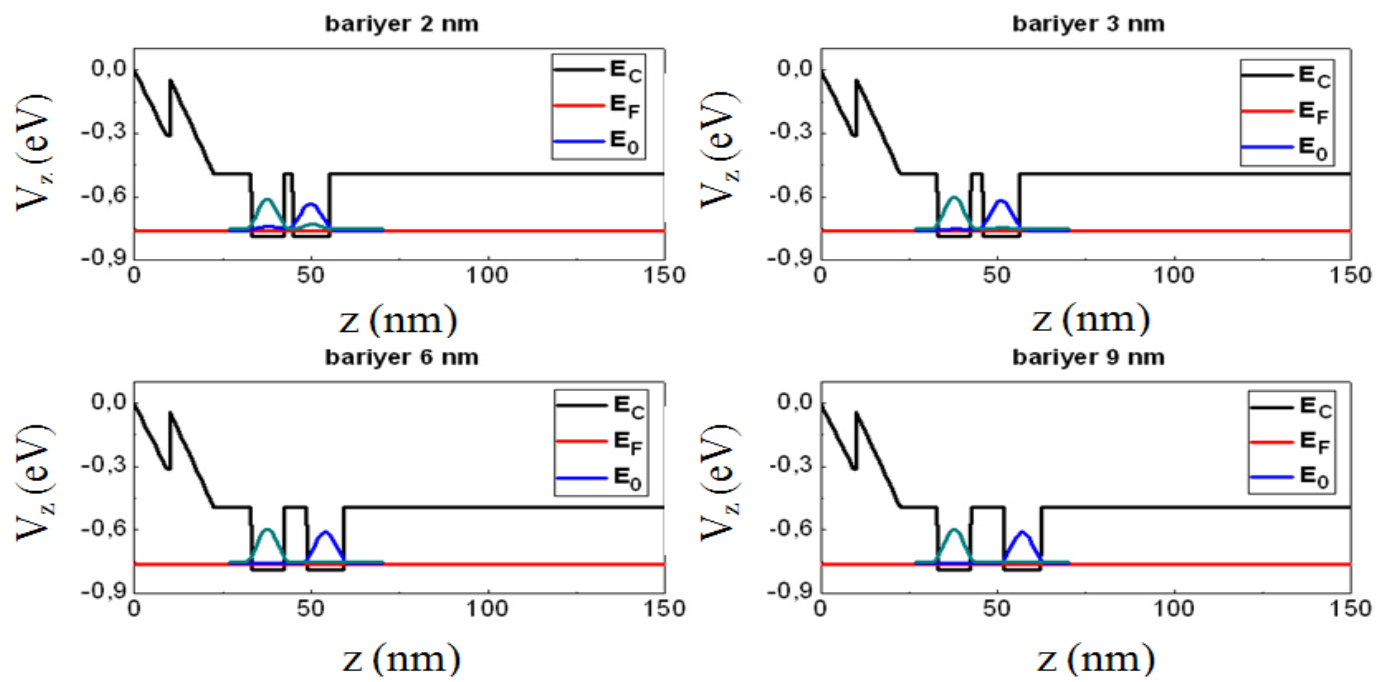

Şekil 5. Farklı bariyer kalınlıkları için elde edilen şekiller: (a) $2 \mathrm{~nm}$, (b) $3 \mathrm{~nm}$, (c) $6 \mathrm{~nm}$, (d) $9 \mathrm{~nm}$ bariyer kalınlıkları için.

\subsection{Kenar potansiyeli sıfırda tutulmuş heteroyapı için sistematik inceleme}

Burada katkılama katmanıyla kuyu arasındaki mesafe yalnızca 10,4 nm’dir. Yüksek mobiliteli örnekler elde edebilmek için donör katmanıyla kuyu arasındaki $\mathrm{Al}_{\mathrm{x}} \mathrm{Ga}_{1-\mathrm{x}} \mathrm{As}$ tabakasının kalınlığı önemli bir parametre olarak ortaya çıkmaktadır.

$\mathrm{Bu}$ ayıracın kalınlığını mobiliteyi azaltmayacak bir miktarda tuttuğumuzda tek tabaka deltakatkılama yeterli olmamakta, çift donör katmanı yapılması gerekmektedir. Mobilite, sisteme elektron sağlayan donörlerle iki boyutlu elektron gazı (2DEG) arasındaki mesafenin büyümesiyle artmaktadır. Bu duruma modülasyon katkı adı verilmektedir.

Şekil 6 da $10 \mathrm{~nm}$ kalınlığında simetrik iki kuyu (QW1 ve QW2) arasında 3 nm'lik bir bariyer vardır. Ayırıcı ara tabakaların kalınlığı sol için 72 nm, sağ için 800 nm olarak alınmıştır. Katkılama yoğunluğu $10^{19}$ mertebesindedir. En son tabaka (Cap layer) GaAs sol için $15 \mathrm{~nm}$, sağ için $20 \mathrm{~nm}$ ile yapı tamamlanmıştır. Ek olarak, yapının son tabakası GaAs katmanı sıfır potansiyelde tutulmuştur.

Şekil 6 ile verilen örnek için farklı katkılama yoğunlukları ile bant profilinin nasıl değişeceği Şekil 7'de görülmektedir. Zayıf katkı durumunda (kırmızı ve siyah çizgiler) elektronlar yüzeye yerleşmektedir. Sonuç olarak yeterince zayıf katkı için kuyu bölgesinde elektron yerelleşmemektedir. Donör sayısı arttırıldığında normal düzey katkılamada (pembe çizgi) dipol potansiyeli yapı içerisinde özellikle de kuantum kuyu bölgesinde azalmaktadır. Eğer katkı daha da arttırılılırsa kuantum kuyudaki en düşük enerji özdeğeri Fermi enerjisinden daha düşük olur ve böylece 2DEG oluşmuş olur. Donör sayısı1 daha da arttırıldığında (aşırı katkılama) Şekil 7'de (mavi çizgi) donör tabakasının bulunduğu bölgelerde paralel kuantum kuyuları meydana gelmektedir. 


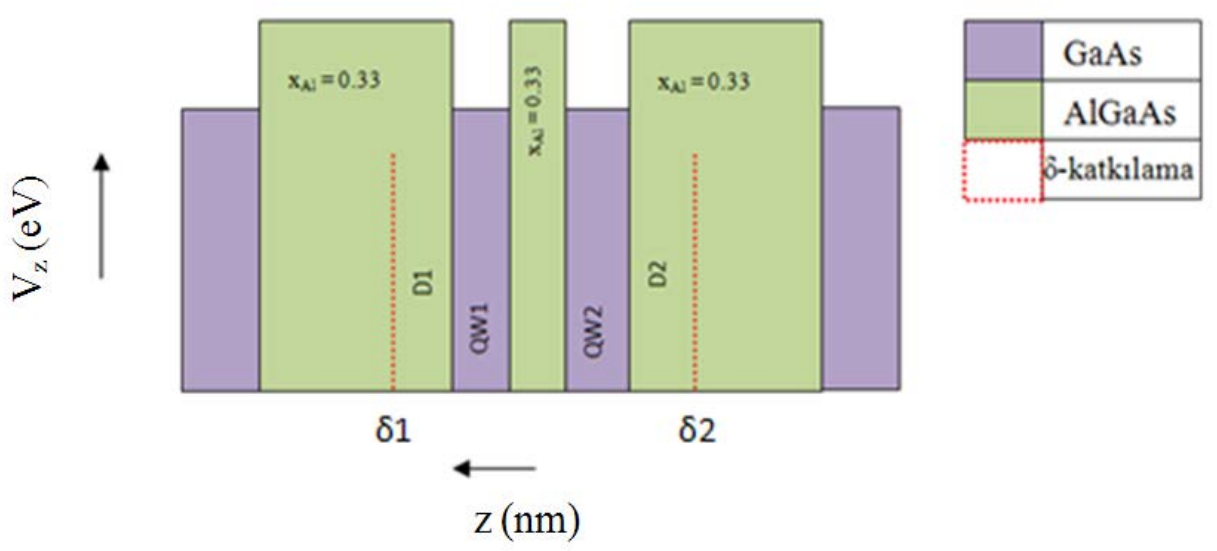

Şekil 6. İki farklı heteroyapının iletkenlik bant durumları

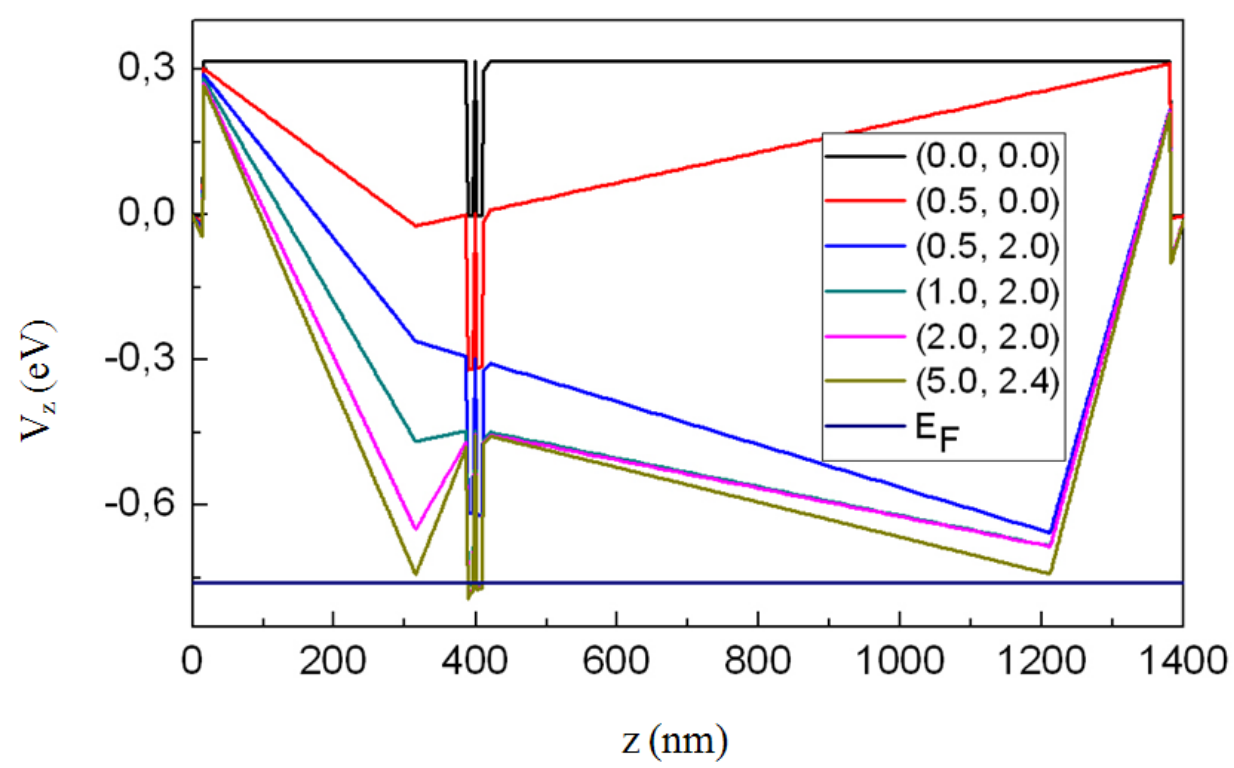

Şekil 7. İki kuyulu bir sistemde potansiyel profili

Çift kuyunun sol ve sağ donör katkısı $\left(5 \times 10^{19} \mathrm{~cm}^{-3}\right)$ ve donörler ile kuyular arasındaki mesafe eşit alındığında simetrik kuyular oluşmakta ve kuyular içerisindeki elektron yoğunluğu birbirine eşit olmaktadır (Şekil 8). Burada açıkça görüldüğü gibi sisteme elektron sağlayan donör katkılamasının hepsi iyonize olmamıştır. Bu durumda ayrıca Şekil 8 (d)'de görüldüğü üzere iyonize yük yoğunluğu $5 \times 10^{19} \mathrm{~cm}^{-}$ ${ }^{3}$ den daha düşüktür. Yani serbest elektronların bir kısmı donör katkı bölgesinde lokalize olmuştur denilebilir.

Şekil 8 Heteroyapının bant profili ve elektron yoğunlukları. (a) İletkenlik bandında kuantum kuyularının potansiyel profili, (b) donor katkılama oran $5 \times 10^{19} \mathrm{~cm}^{-3}$ olan heteroyapının iletkenlik bant profili, (c) kuyular içerisindeki elektron yoğunluğu dağılımı, (d) negatif bölge elektronların yerelleştiği bölgeyi ve pozitif bölge pozitif yük yoğunluğunu göstermektedir. 
a)
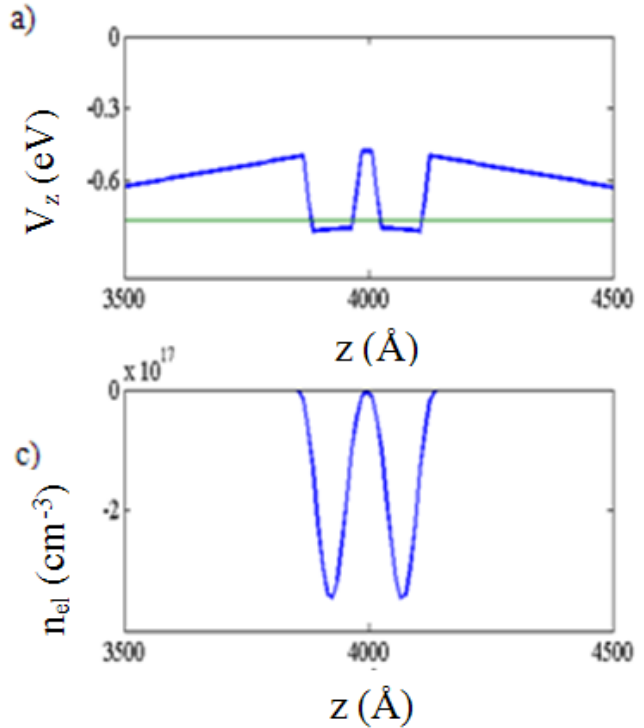

b)

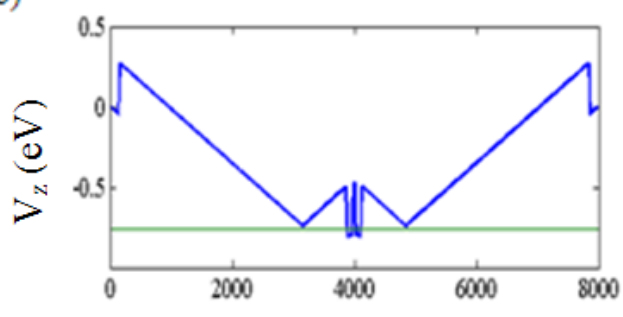

$\mathrm{Z}(\AA)$

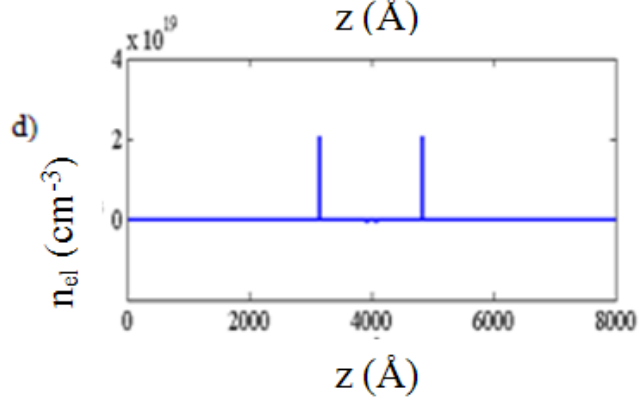

Şekil 8. Heteroyapının bant profili ve elektron yoğunlukları
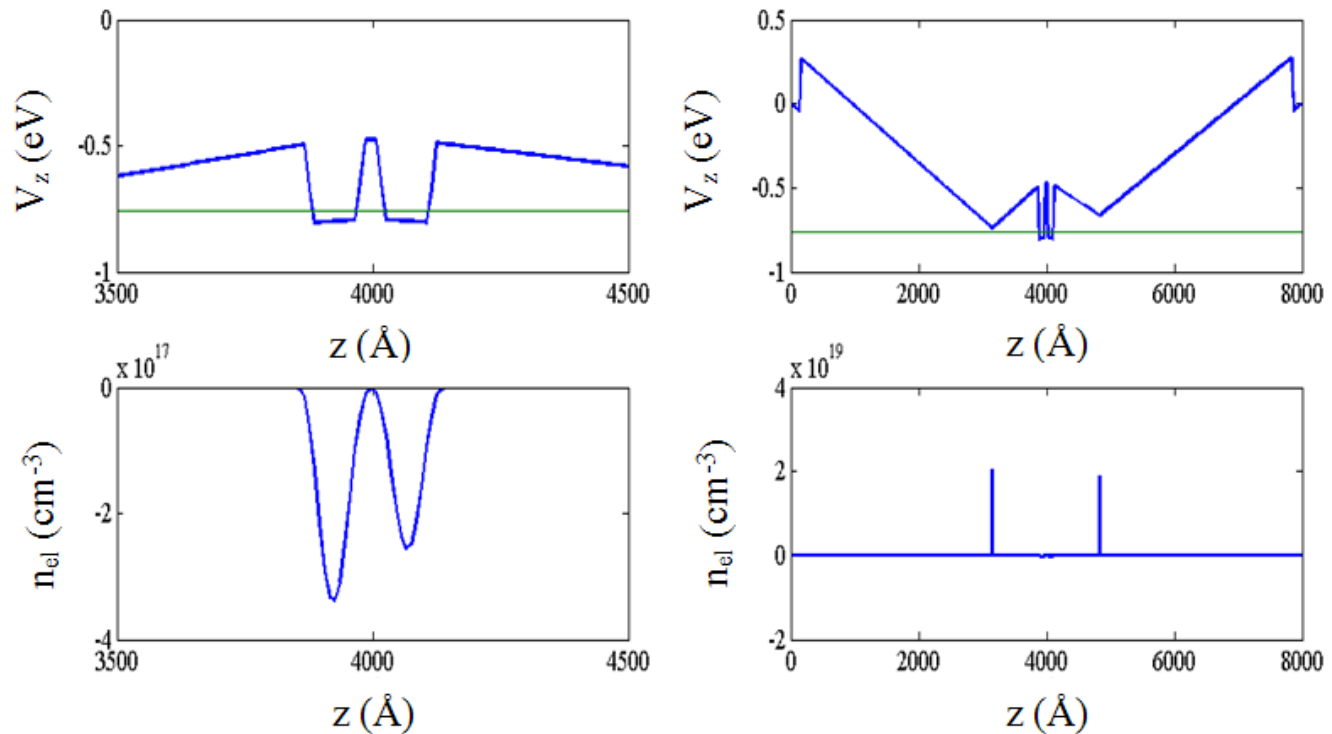

Şekil 9. Donor katkı oranı sol taraf için $5 \times 10^{19} \mathrm{~cm}^{-3}$ ve sağ taraf için $2 \times 10^{19} \mathrm{~cm}^{-3}$ olan sistemin potansiyel profili ve yük dağılımı gösterimi

Farklı donor katkılamalarının etkisine bakmak için Şekil 6 ile verilen örneğin tüm parametreleri sabit tutulup sadece sağ donor katkı oranı $5 \times 10^{19} \mathrm{~cm}^{-3}$ den $2 \times 10^{19} \mathrm{~cm}^{-3}$ ye indirilmiştir. Böylece, heteroyapının elde edilen potansiyel profili ve yük yoğunluğu dağılımı Şekil 9 da görüldüğü gibi bir değişim göstermektedir.

\section{Tartışma ve Sonuç}

$\mathrm{Bu}$ çalışmada farklı enerji bant aralıklarına sahip AlGaAs/GaAs heteroyapısında AlGaAs tabakasına Si katkılama, bu tabaka için donör etkisi görür ve iyonize olarak elektronların büyük bir 
çoğunluğunu sisteme verirken geride büyük çoğunluğu pozitif iyonlardan oluşan bir delta katman bırakır. Elektronlar, bekleneceği gibi daha düşük enerjili durumda olmak için GaAs tabakalara doğru hareket edeceklerdir. Yüzeye yakın katkılama elektronların önce yüzeye hareketine sebep olurken Coulomb etkileşmeleri sonucunda elektronların bir kısmı alttaki GaAs tabakasına itilecektir. Pozitif delta katmanı etkisiyle elektronların büyük çoğunluğu eklem bölgesinde toplanacaktır. Bu durumun bir etkisi olarak potansiyel bükülmeleri gerçekleşecektir.

Eşit kuyu genişliklerinde ve D1 ₹ D2 durumunda farklı donör yoğunluklarına sahip bir yapı oluşturulduğunda uygun donör katkılama değerleri için tünelleme olabileceği görülmüştür. Ayrıca farklı konumda farklı donör yoğunluk değerleri de heteroyapının bant bükümünü ve kuyuların şeklini farklı etkilemektedir. İki kuyulu yapıda, katkılama bölgesinin kuyudan uzaklığı mobilite üzerine etkin bir rol oynamaktadır. Ancak kuyu ile katkılama katmanı arasındaki mesafe büyüdükçe elektronların kuyular içerisinde yerleşmesi zorlaşmaktadır. Bu nedenle kuyuların sağında ve solunda çift donör katkılaması yapılmaktadır. Çift donör katkılamasının asitmetrik yapılması durumunda kuyular içerisine yerleşen elektron yoğunluklarının asimetrik olduğu gözlemlenmiştir. Şüphesiz bu tür yapıların sıcaklık bağımlılığı ve her bir kuyunun farklı bir genişlikte modellenmesi de oldukça önemlidir, fakat burada bu etkiler araştırılmamıştır.

\section{Kaynaklar}

[1] Türkoğlu A., "GaAs- $\mathrm{Al}_{\mathrm{x}} \mathrm{Ga}_{1-\mathrm{x}} \mathrm{As}$ Heteroyapı ve Çoklu Kuantum Kuyu IR Fotodedektörün Elektro-optik Özelliklerinin İncelenmesi”, Cumhuriyet Üniversitesi, Fen Bilimleri Enstitüsü, Doktora tezi, 158, Sivas, 2007.

[2] Stradling R.A., “The Electronic Properties and Applications of Quantum Wells and Superlattices of III-V Narrow Gap Semiconductors”, Brazilian J. Phys., 26, (1), 7-20, 1996

[3] Chalker J.T., Gefen Y., Veillette M.Y., "Decoherence and Interactions in an Electronic MarchZehnder Interferometer”, Phys. Rev. B, 76, (8), 1-11, 2007

[4] Mese A.I., Bilekkaya A., Arslan S., Aktas S., Siddiki A., "Investigation of The Coupling Asymmetries at Double-Slit Interference Experiment Samples” J. Phys. A : Math. Theor., 43, (35), 1-8, 2010

[5] Ihnatsenka S., Zozoulenko I.V., "Interacting Electrons in The Aharonov-Bohm Interferometer”, Physical Review B, 77, (23), 1-9, 2008

[6] Morgan C.G., Kratzer P., Scheffler M., “Arsenic Dimer Dynamics During MBE Growth: Theoretical Evidence for a Novel Chemisorption State of $\mathrm{As}_{2}$ Molecules on GaAs Surfaces” Phys. Rev. Lett., 82, (24), 4886-4889, 1999

[7] Erol A., "Yüzey Işıması Yapan Düşük Boyutlu Yapılarda Bragg Yansıma Olaylarının İncelenmesi”, İstanbul Üniversitesi, Fen Bilimleri Enstitüsü, Doktora tezi, 138, İstanbul, 2002.

[8] Picciotto R.de, Stormer H.L., Yacoby A., Pfeiffer L.N., Baldwin K.W., West K.W., “2D-1D Coupling in Cleaved Edge Overgrowth”, Phys. Rev. Lett,. 85, (8), 1730-1733, 2000

[9] Picciotto R.de, Stormer H.L., Yacoby A., Pfeiffer L.N., Baldwin K.W., West K.W., “Transport in Cleaved-Edge Overgrowth Wires”, Physica E, 9, (1), 17-21, 2011 
[10] Grayson M., Roth S.F., Xiang Y., Fischer, F, Schuh D., Bichler M., "Four-Point Measurements of n- and p-type Two-Dimensional Systems Fabricated with Cleaved-Edge Overgrowth”, Appl. Phys. Lett., 87, (21), 1-2, 2005

[11] Erkarslan U., Oylumluoglu G., Grayson M., Siddiki A., “The visibility of IQHE at sharp edges: experimental proposal based on interactions and edge electrostatics”, New Journal of Physics, 14, 023015-023020, 2012

[12] Cicek E., Mese A.I, Ulas M., Siddiki A., "Spatial Distribution of the Incompressible Strips at AB Interferometer”, Physica E : Low-dimensional Systems and Nanostructures 42, (4), 1066-1068, 2010

[13] Ando T., Fowler A., Stern F., “Electronic Properties of Two-Dimensional Systems”, Rev. Mod. Phys, 54, (2), 437-672, 1982

[14] Tsui D. C., Störmer H.L., Gossard A.C., “Zero-Resistance State of Two-Dimensional Electrons in a Quantizing Magnetic Field”, Phys. Rev. B, 25, (2), 1405-1407, 1982

[15] Matveev K.A., “Coulomb Blockade at Almost Perfect Transmission”, Phys. Rev. B, 51, (3), 1743-1751, 1995

[16] Adachi S., “Properties of Aluminium Gallium Arsenide”, INSPEC, London, 341-362, 1993

[17] Siddiki A., "Self-Consistent Coulomb Picture of an Electron-Electron Bilayer System”, Phys. Rev. B, 75, (15), 1-12, 2007 